\title{
Faculty Development for Medical Teachers: An Effective Mechanism to Foster Professional Development
}

\author{
Mohd Zarawi Mat Nor \\ Department of Medical Education, School of Medical Sciences, \\ Universiti Sains Malaysia, Kelantan, MALAYSIA
}

To cite this article: Mat Nor MZ. Faculty development for medical teachers: an effective mechanism to foster professional development. Education in Medicine Journal. 2019;11(3):63-68. https://doi.org/10.21315/eimj2019.11.3.7

To link to this article: https://doi.org/10.21315/eimj2019.11.3.7

\begin{abstract}
The ultimate aim of faculty development programmes (FDPs) is to boost teachers' competence in their journey of becoming a respectable educator. It takes place when a faculty member joins such activity with a hope of cultivating their knowledge and skills in desired areas such as pedagogy, research, motivation, and administration. However, to design the best practices of FDPs, it needs a great deal of consideration on numerous factors. This paper discusses principles of the best practice in FDPs, challenges and its solutions, its impacts on professional identity, and finally highlights the future trend of FDPs. Since it is beneficial in fostering professionalism of a faculty member, it is important for school administrators to address FDPs as a prominent agenda in seeking a professional medical teacher.
\end{abstract}

Keywords: Faculty development programme, Medical teachers, Professional development

\section{INTRODUCTION}

Faculty development programme (FDP), which is also known as instruction development, organisational development, career development, and personal development (1) in a higher education institution, was conceptualised in 1975, whereby Kamel (2) has recognised such activities in enhancing teacher's professionalism. Currently, FDPs have been intensively emphasised (3) in the education setting including medical education (4). Undoubtedly, since its emergence, FDPs have contributed a significant amount of benefits to its participants including content knowledge, pedagogy skills, research, and educational management (5-7). Faculty development is a similar term used for staff development and professional development, and is an ongoing professional learning for educators in an educational setting (8). Considering this feature, FDP is regarded as strategic activities purposely planned to enhance teachers' competence in professional and personal domains (9). It can be done by training and sensitising teachers regarding pedagogy, advanced knowledge and clinical skills required in accomplishing the role as knowledgeable and effective educators, administrators, researchers, and mentors, and support clinicians to gain capability in communication skills and update knowledge 
through information and research methodology tools (10).

In the context of medical education, FDPs have shared similar features of other fields such as engineering, business, marketing, and social sciences. However, an additional feature of FDP in the context of medical education is, it has its precise objective, which is to ensure the patient's welfare (11). This paper discusses principles of the best practice FDPs, challenges and its solutions, its impacts on professional identity besides highlighting the future trend of FDPs.

\section{PRINCIPLES OF FACULTY DEVELOPMENT}

\author{
Effective professional development is \\ intensive, ongoing, and connected to \\ practice; focuses on the teaching and \\ learning of specific academic content; \\ is connected to other school initiatives; \\ and builds strong working relationships \\ among teachers. Linda Darling- \\ Hammond and Ruth Chung Wei \\ (2009) (12).
}

To design effective FDPs is a big challenge. It needs a great amount of knowledge, commitment, and skill from the organisers. However, the works can be easier if they are provided by a set of principles regarding the best practice of FDPs. Considering this, principles of FDPs that the organisers need to consider while planning and implementing the FDPs are suggested here.

\section{Principle 1: FDP is a Life-long Learning Process}

Lifelong learning is the "ongoing, voluntary, and self-motivated pursuit of knowledge for personal or professional enhancement" (13). It can occur in the form of formal learning or informal learning, or self-directed learning (14). In the context of FDPs, it can be realised not only in classrooms but also in the format of dialogue or small group discussion $(15,16)$.

\section{Principle 2: Adult Learning Features is a Considerable Item in FDPs}

An initiative of FDP should consider the characteristics of the participants itself. Since they are adult learners, it is important to fully understand the principles of adult learners. Therefore, FDPs must be able to align with the nature of adult learners. For instance, they need to be actively involved in the proposed discussion and speakers acts as a facilitator rather than a speaker (17).

FDP, which has been based on adult learning principles, adult learning theory and practice have strongly influenced faculty development approaches for both Problem Based Learning (PBL) and other educational endeavours (11). Importantly, they have also been shown to enhance participants' satisfaction with faculty development $(15,16)$. According to Steinert (18), this approach is effective and should continue to guide the implementation of all faculty development programmes irrespective of their focus or format. Adult learning principles characterise learners as being highly self-directed and having many prior experiences as a learning resource. Leslie et al. (15) has proposed various key principles to guide faculty development in medical education. These include communicating with faculty about "why" they need to learn something new, creating a "need-to-know experience" to increase faculty interest in learning, and focusing programmes on concrete tasks and skills with immediate opportunities for application (18).

\section{Principle 3: Application of an integrated method in FDPs}

Currently, the use of ICT component in a training session is a necessity including in FDPs. As participants' background varies, the usage integrated approach in training session is aligned with the group variation (19). For example, application of ICT is consistent with the visual learners. Therefore, considering technology 
pedagogical content knowledge (TPACK) in a learning process will be a good mechanism to tackle the variety of needs of FDP participants. Apart from that, the learning sessions must be in experiential learning format; the participants of FDP need to apply what they have learned during the activities and receive feedback on the learned skills.

\section{Principle 4: Collaboration and Reflective Learning}

Collaboration characterises the process as "an effective interpersonal process that facilitates the achievement of goals that cannot be reached when individual professionals act on their own". It can be realised through a professional networking among clinician and non-clinician faculty members. On the other hand, utilisation of reflective thinking is needed to enhance quality of service after joining FDPs. In doing this, they receive systematic and constructive feedbacks, which then lead them to fully understand the strengths and weaknesses of their performances. Collaboration is also important to access resources and reduce costs, furthermore, it will be the best practice to maximise the use of limited sources while maintaining high performance.

\section{Principle 5: Assessment Part of Learning Package}

Assessment is important to reflect the achievement of a faculty development activity. Thus, evaluation should become part of the entire package of FDPs. It includes effective evaluation to assess the achievement of an activity objective or need assessment to predict the actual needs of FDPs among faculty members.

\section{CHALLENGES AND SOLUTIONS}

Although FDPs have received intensive attention due to its benefits to the faculty, it has numerous challenges, which affect the superiority of the FDPs. In a study conducted by the Association of Medical Education in Europe, they identified that the challenges were lack of academic recognition $(40 \%)$, funding (36\%), faculty development (24\%), time for medical education issues $(22 \%)$, and institutional support (21\%) (20). Another similar study showed that lack of human resources, time constraint, and lack of facilities were among the contributing factors to the effectiveness of FDPs (9). Apart from that, lack of senior professor in a subject matter has also become a big challenge to produce high quality FDPs (21).

Besides, lack of competence in ICT was also a reason why medical teachers become poor to maximum use of ICT in their teaching process. In addition, the $21 \mathrm{st}$ century learning trends/pedagogy needs a teacher who can integrate online learning space with technology, pedagogy, and content knowledge (22). Thus, a specific body such as a committee or special task which focuses on such aspect is crucial to ensure the needs of ICT competency is met. If possible, it is suggested that the faculty prioritise this skill in a comprehensive package of FDPs.

Since the increment of multiculturalism and diversity of students in higher education including the school of medical sciences, it is crucial for the faculty developer to consider such issue as an area of topic in FDPs. It is due to it being closely related with the learning environment. In this regard, the FDP organiser need to respond to the question: what kind of FDPs need to be considered to support faculty with students who learn most effectively in different culture through FDPs $(3,23)$.

To tackle the issue of lack of human resource to promote effective FDPs, it is crucial to develop international or national networking, which functioned in expertise exchange and professional collaboration among medical teachers nationally or internationally. In this regard, an active involvement from the government, private 
agencies, and individual as well could be taken into account.

Recognising FDPs experts as a professional trainer by rewarding them with a significant promotion or other advantages is believed to be a fruitful method to minimise the related problem. Such rewards can be internal or external motivation to the certain group of faculty developers.

\section{IMPACTS OF FDP ON TEACHER'S COMPETENCY - A SURVEY FINDING}

Undoubtedly, FDPs have benefited faculty members in many ways. It includes not only junior teachers but also seasoned ones. It can be measured in the behaviour, cognitive, and attitude changes.

In a previous study, three impacts of FDPs to the professionalism of medical teachers were identified, which were self-awareness regarding the basic task in teaching process, maturity on the teacher-student interaction, and awareness on the community engagement (24). In another study, the result of an interview among the participants of an FDP showed that they have become aware regarding the importance of teaching and learning skills. This can be seen through the following statement; "I was given a teaching time slot, and I just satisfy that requirement... I didn't really appreciate to understand the bigger picture of the whole situation. When the students come around (for) my tuition, what you are doing is you are teaching your specialty.” (24).

Regarding maturity on the teacher-student interaction, two participants of a study expressed these opinions: (a) "I was looking for idea (on) how to interact with student ... I would like to have more interaction with the students and the reason that I couldn't have a good teaching (was) maybe I am not very effective in interaction." and (b) "We don't really have a structured methodology as to how we teach, a lot of time, it is based on our anecdotal experience, what we learnt from our previous teachers, we try to apply and modify accordingly."

Pertaining community engagement, an interviewee has shared his idea as follows: "In the United Kingdom, I was involved in a few modules around medical education, so I have done a few assignments based on that as well...Workplace-based assessment interests me, maybe because I used that in the United Kingdom and here, but the way (they are) used is different...Here is more of a summative assessment rather than a formative assessment."

Supporting the aforementioned subject matter, a study found that FDPs have contributed to the professional identity in the following terms; personal growth, professional growth, and self-reflective practice. These findings then have been described in detail as self-awareness, intention, internal satisfaction, career pathway, maintaining professional skills, acquiring new knowledge, identifying strengths and weaknesses, and identifying areas for improvement mechanism (9).

\section{THE FUTURE TREND OF FDPS}

Since the nature of knowledge and skills is not a static one, possible changes to its features are high. For instance, the shifting of learning instruments will lead the changing of the education environment itself. Therefore, FDP will focus on providing coaching, ongoing feedback, and resources for learning opportunities rather than as an information provider. Based on such scenario it is assumed that the future FDPs will take place with huge consideration of the following aspects: (a) diversity of members must work together to better align with the school's vision and missions. It includes support staff, administration, academician and as well as the community. They need to be exposed to their expected roles to accomplish the school's vision and mission; (b) development of faculty's multitasking 
competencies for future organisational goals. Stimulating full potential of all staffs is compulsory so that the schools are really prepared to hand over to the new generation; (c) emphasise communication skills between administration-lectures, lecturers-students, students-patients and communities; (d) focus on participants centred approach rather than speaker centred. It means participants of the FDPs must be actively involved during the sessions so that their true potential and performance will be maximally explored; and (e) recognising digital and mobile content as a critical component in delivering system. This is consistent with the current development; whereby online learning has become the main medium in teaching and learning process.

\section{CONCLUSION}

In conclusion, it is clear that FDPs are crucial to enhance teachers' competence in numerous domains to make them credible in their service. Among the beneficial domains are teaching and learning, research, personal development, and administration. These benefits can be achieved should the FDPs itself takes place in a systematic plan based on the main principles as previously discussed. Consistent with the rapid changed in the education world, especially for medical education, the faculty members face huge challenges in making FDPs as a meaningful, joyful, and interesting activity. Thus, the faculty developers need to be creative in tackling these challenges. Finally, to make FDPs relevant at all time, the faculty members must consider the potential trend in the future.

\section{REFERENCES}

1. Camblin LD, Steger JA. Rethinking faculty development. Higher Education. 2000;39(1):1-18. https://doi.org/10.1023/ A: 1003827925543
2. Kamel AM. Role of faculty development programs in improving teaching and learning. Saudi Journal of Oral Sciences. 2016;3(2):61-8. https://doi. org/10.4103/1658-6816.188073

3. Austin AE, Sorcinelli MD. The future of faculty development: where are we going? New Dir Teach Learn. 2013;2013(133):8597. https://doi.org/10.1002/tl.20048

4. Gruppen LD, Frohna AZ, Anderson RM, Lowe KD. Faculty development for educational leadership and scholarship. Acad Med. 2003;78(2):137-41. https://doi. org/10.1097/00001888-200302000-00007

5. Rosenthal S, Gamble C, Landers S, Stanberry L. Faculty development programming within pediatric departments: is it really happening? What their webpages tell us. J Pediatr. 2019;206:4-5. https://doi. org/10.1016/j.jpeds.2018.12.059

6. Saiki T, Imafuku R, Pickering J, Suzuki Y, Steinert Y. On-site observational learning in faculty development: impact of an international program on clinical teaching in medicine. J Contin Educ Health Prof. 2019;39(2):144-51. https://doi.org/10.1097/ CEH.0000000000000253

7. Sorcinelli MD, Austin AE, Eddy PL. Creating the future of faculty development: learning from the past, understanding the present. San Francisco, California: JosseyBass; 2006.

8. Lawler PAK, Kathleen P. Planning for effective faculty development: using adult learning strategies. Malabar, Florida: Krieger Pub Co.; 2000.

9. Nor MZM. Contribution of faculty developmental programmes to professional identity development of medical educators in Malaysia: a phenomenological study. Journal of Taibah University Medical Sciences. 2019;14(4):324-331. https://doi. org/10.1016/j.jtumed.2019.06.001 
10. Douglass K, Williams A. faculty development program for emergency medicine physicians in India: a pilot program. AEM e Educ Train. 2019;3(1):338. https://doi.org/10.1002/aet2.10125

11. McLean M, Cilliers F, Van Wyk JM. Faculty development: yesterday, today and tomorrow. Med Teach. 2008;30(6):555-84. https://doi.org/10.1080/01421590802109834

12. Darling-Hammond L, Wei RC, Andree A, Richardson N, Orphanos S. Professional learning in the learning profession. Washington, DC: National Staff Development Council; 2009. p. 12.

13. Butcher W, Street P-A. Lifelong learning with older adults. Australasian Public Libraries and Information Services. 2009;22(2):64.

14. Longworth N. Making lifelong learning work. Abingdon, United Kingdom: Routledge; 2019. https://doi. org/10.4324/9781315042084

15. Leslie K, Baker L, Egan-Lee E, Esdaile M, Reeves S. Advancing faculty development in medical education: a systematic review. Acad Med. 2013;88(7):1038-45. https://doi. org/10.1097/ACM.0b013e318294fd29

16. Steinert Y, Mann K, Anderson B, Barnett BM, Centeno A, Naismith L, et al. A systematic review of faculty development initiatives designed to enhance teaching effectiveness: a 10-year update: BEME Guide No. 40. Med Teach. 2016;38(8):76986. https://doi.org/10.1080/0142159X.2016. 1181851

17. Cercone K. Characteristics of adult learners with implications for online learning design. AACE Journal. 2008;16(2):137-59.
18. Steinert Y. Faculty development in the new millennium: key challenges and future directions. Med Teach. 2000;22(1):44-50. https://doi.org/10.1080/01421590078814

19. Chen C-J. Differences between visual style and verbal style learners in learning English. Computer-assisted language learning: concepts, methodologies, tools, and applications. Pennsylvania: IGI Global; 2019. p. 1894-908. https://doi. org/10.4018/978-1-5225-7663-1.ch090

20. Huwendiek S, Mennin S, Nikendei C. Medical education after the Flexner report. N Engl J Med. 2007;356(1):90-1. https://doi.org/10.1056/NEJMc062922

21. Mukhtar F, Chaudhry AM. Faculty development in medical institutions: where do we stand in Pakistan? Journal of Ayub Medical College Abbottabad. 2010;22(3):210-3.

22. Baran E, Canbazoglu Bilici S, Albayrak Sari A, Tondeur J. Investigating the impact of teacher education strategies on preservice teachers' TPACK. Brit J Educ Technol. 2019;50(1):357-70. https://doi.org/10.1111/ bjet. 12565

23. Sorcinelli MD. Faculty development: the challenge going forward. Peer Review. 2007;9(4): 4-8.

24. Lee SS, Dong C, Yeo SP, Gwee MC, Samarasekera DD. Impact of faculty development programs for positive behavioural changes among teachers: a case study. Korean J Med Educ. 2018;30(1):1122. https://doi.org/10.3946/kjme.2018.77 